\title{
REVIEWS
}

\section{A Systematic Review of Conceptual Frameworks of Medical Complexity and New Model Development}

\author{
Leah L. Zullig, PhD 1,2,3,5, Heather E. Whitson, MD 4,5,6,7,8, Susan N. Hastings, MD",4,5,6,7, \\ Chris Beadles, MD, PhD 5,9 , Julia Kravchenko, MD, PhD 5,10, Igor Akushevich, PhD 5,11 , and \\ Matthew L. Maciejewski, PhD ${ }^{1,2,5}$
}

\begin{abstract}
${ }^{1}$ Center for Health Services Research in Primary Care, Durham Veterans Affairs Medical Center, Durham, NC, USA; ${ }^{2}$ Division of General Internal Medicine, Department of Medicine, Duke University Medical Center, Durham, NC, USA; ${ }^{3}$ Duke Cancer Institute, Duke University Medical Center, Durham, NC, USA; ${ }^{4}$ Geriatrics Research, Education and Clinical Center, Durham Veterans Affairs Medical Center, Durham, NC, USA; ${ }^{5}$ mbulatory Care Service, Durham Veterans Affairs Medical Center, Durham, NC, USA; ${ }^{6}$ Division of Geriatrics, Department of Medicine, Duke University, Durham, NC, USA; 7 Center for the Study of Aging and Human Development, Duke University, Durham, NC, USA; ${ }^{8}$ Depart ment of Ophthalmology, Duke University Medical Center, Durham, NC, USA; ${ }^{9}$ RTI, Chapel Hill, NC, USA; ${ }^{10}$ Department of Surgery, Duke University Medical Center, Durham, NC, USA; ${ }^{1}$ Social Science Research Institute, Durham, NC, USA.
\end{abstract}

BACKGROUND: Patient complexity is often operationalized by counting multiple chronic conditions (MCC) without considering contextual factors that can affect patient risk for adverse outcomes.

OBJECTIVE: Our objective was to develop a conceptual model of complexity addressing gaps identified in a review of published conceptual models.

DATA SOURCES: We searched for English-language MEDLINE papers published between 1 January 2004 and 16 January 2014. Two reviewers independently evaluated abstracts and all authors contributed to the development of the conceptual model in an iterative process.

RESULTS: From 1606 identified abstracts, six conceptual models were selected. One additional model was identified through reference review. Each model had strengths, but several constructs were not fully considered: 1) contextual factors; 2) dynamics of complexity; 3) patients' preferences; 4) acute health shocks; and 5) resilience. Our Cycle of Complexity model illustrates relationships between acute shocks and medical events, healthcare access and utilization, workload and capacity, and patient preferences in the context of interpersonal, organizational, and community factors.

CONCLUSIONS/IMPLICATIONS: This model may inform studies on the etiology of and changes in complexity, the relationship between complexity and patient outcomes, and intervention development to improve modifiable elements of complex patients.

KEY WORDS: patients; multiple chronic conditions; multimorbidity; complexity; resilience; patient goal.

J Gen Intern Med 31(3):329-37

DOI: $10.1007 / \mathrm{s} 11606-015-3512-2$

(c) Society of General Internal Medicine 2015

\section{INTRODUCTION}

The management of patients with multiple chronic conditions (MCC) is challenging. Clinical practice guidelines rarely

Received June 10, 2015

Revised August 13, 2015

Accepted August 31, 2015

Published online September 30, 2015 address multiple conditions. Care plans for MCC patients based on a single-disease paradigm may be impractical or harmful. ${ }^{1,2}$ There is scant evidence to inform optimal care management of MCC patients because most care models are ineffective (e.g., Medicare Coordinated Care Demonstration), ${ }^{3,4}$ or effective but not scalable (e.g., Program of AllInclusive Care for the Elderly (PACE)). ${ }^{5}$ In the absence of evidence-based guidelines or care models, patients and providers struggle to prioritize care decisions based on patient preferences and clinical judgment. Others have noted that care decisions for patients with MCC should "evolve from a disease orientation to a patient goal orientation" that takes into account an individual's unique priorities. ${ }^{2,6}$ Acknowledging challenges presented by MCC, the Department of Health and Human Services released a strategic framework to improve the health of MCC patients. $^{7}$ In support of this framework, the Agency for Healthcare Research and Quality (AHRQ) funded research to generate evidence pertaining to $\mathrm{MCC}{ }^{8}$

Patient complexity is a related but distinct concept from MCC. Patient complexity recognizes that for patients with functional and health limitations, some key challenges are social or non-medical issues that are not easily amenable to healthcare intervention. The complicated interplay between medical and non-medical factors that influence health outcomes has been previously recognized, ${ }^{9,10}$ and may be particularly salient for complex patients. For one example, an MCC orientation ignores social capital, defined as features of social organization and resources available to individuals within a community, that have been associated with health at the level of the person and at the level of society. ${ }^{11}$ To improve the care of complex patients, clinicians must address "extra-medical" challenges, carefully eliciting patients' evolving preferences as well as capacity to self-manage. Complicating non-medical challenges, providers face ongoing and evolving responsibility in a fragmented healthcare system that often lacks incentives for services coordination or meaningful communication about goals and priorities of patients and their families. 
The purpose of this study was to conduct a systematic review of published conceptual models related to MCC or patient complexity. Based on common strengths and consistent gaps in these existing conceptual models, we developed a new conceptual model of patient complexity and associated outcomes. This conceptual model expands the common framing of MCC as synonymous with complexity to one in which $\mathrm{MCC}$ is one facet of complexity. A conceptual model can be useful to illustrate the relationship between complexity and MCC, and to clarify measurement of modifiable patient, provider and health system factors that can ultimately inform care models for complex patients.

\section{METHODS}

\section{Article Identification}

With assistance from a reference librarian, we searched MEDLINE for English-language papers published between 1
January 2004 and 16 January 2014 (Fig. 1), which yielded 1606 unique abstracts. Two reviewers independently evaluated abstracts using a three-level scoring system to rank relevance (e.g., not relevant [0], unclear relevance [1], relevant [2]) for a combined possible score of 0-4. Review criteria included applicability to MCC and/or patient complexity and presentation of a theoretical or conceptual model of health needs or outcomes of MCC/complex patients. Full text articles were reviewed for abstracts receiving a combined score of 34. The review team (LZ, HW, SH, CB, MM) met to reach consensus regarding whether the full text should be reviewed for abstracts with combined scores of 1-2 points.

Fifty-one papers underwent full-text review by two reviewers; the full review team convened for adjudication and to render final decisions by consensus. At the full-text stage, 46 articles were excluded because they did not present a novel conceptual model $(n=23)$, presented a model/framework for clinical care delivery $(n=9)$, applied or referenced an existing conceptual framework without modification $(n=7)$, or
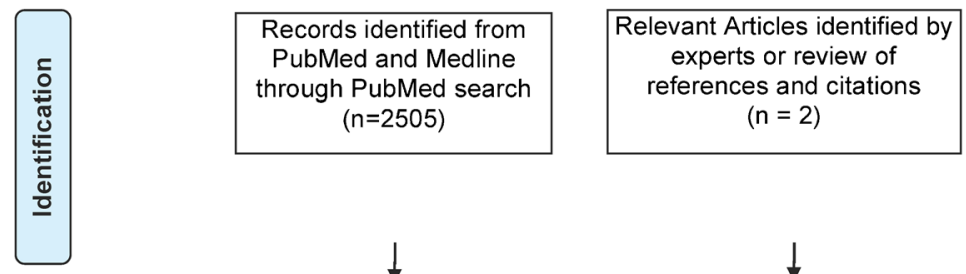
$(n=2505)$

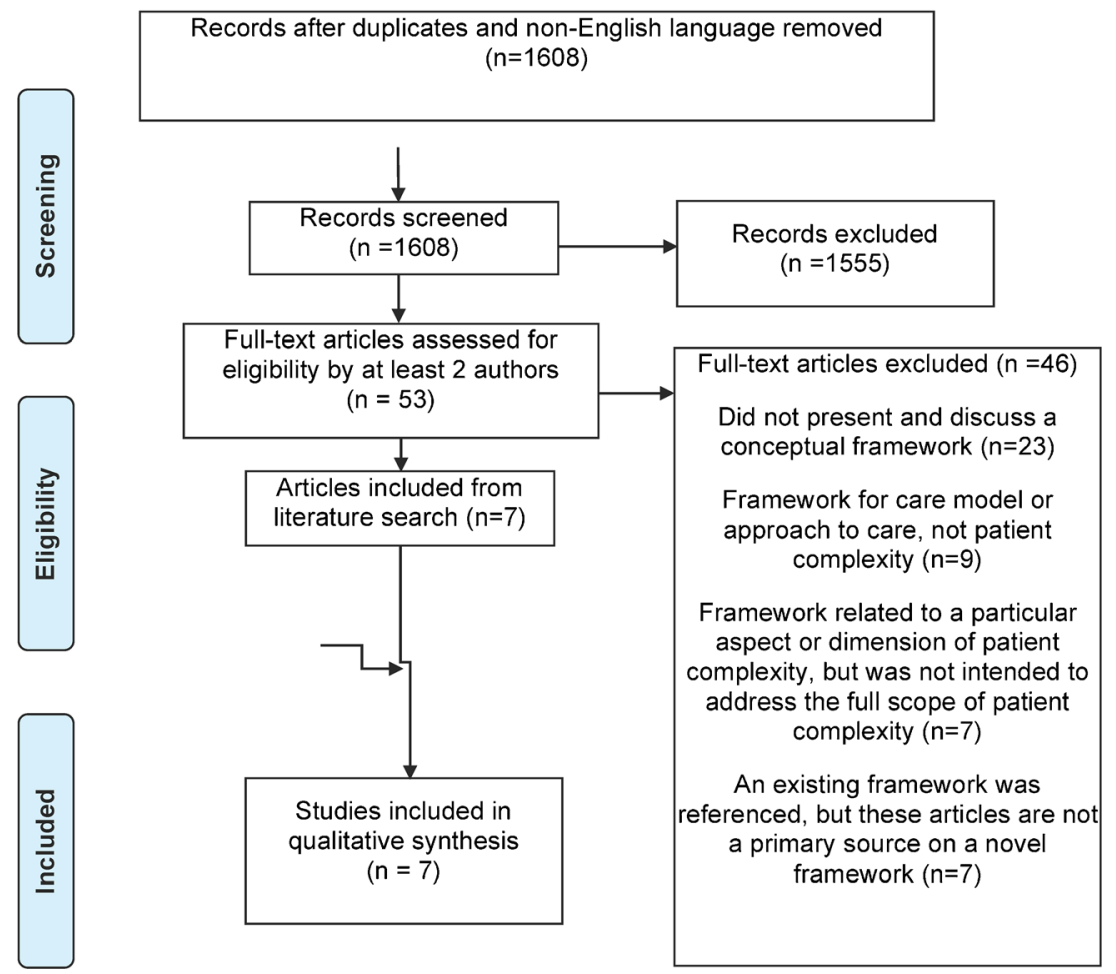

Figure 1 PRISMA Flow Diagram. Legend. Specific search strategy: ((multiple[tiab] AND ("Chronic Disease"[Mesh] OR "Comorbidity"[Mesh] OR comorbidity[tiab] OR comorbidities[tiab] OR comorbid[tiab] OR co-morbid[tiab])) OR "patient complexity" [tiab] OR "multiple chronic comorbidities"[tiab] OR "multiple chronic conditions"[tiab] OR "multiple chronic disease"[tiab] OR "multiple chronic diseases"[tiab]) AND (("Models, Theoretical"[Mesh] OR framework[tiab] OR model[tiab] OR models[tiab]) NOT "Models, Statistical"[Mesh]) NOT (animals[mh] NOT humans[mh]) AND English[la] AND ("2004"[Date - Publication] : "3000"[Date - Publication]). 
presented a model focused on only one dimension (e.g., focusing on a single disease rather than the full scope of medical, psychosocial, and other factors of complexity) $(n=7)$. One conceptual model, ${ }^{12}$ published shortly after the initial abstract identification process, was included because it was relevant and was developed by investigators from the AHRQ MCC Research Network. Citation review revealed a seventh conceptual model ${ }^{13}$ that we also included due to its relevance.

\section{Data Extraction}

Members of the review team (LZ, HW, SH, MM) independently extracted the following data elements from the included articles: 1) objective; 2) personal or individual factors related to complexity; 3 ) external or environmental factors related to complexity; 4) treatment and management factors; 5) whether the model was static or dynamic; 6) whether the model was based on literature, empirical data, or another source; 7) salient themes; and 8) striking gaps. These data elements were finalized after the data extraction form was piloted in a small number of articles and modestly revised for inclusiveness. The review team then met to discuss and synthesize information in an iterative process, considering strengths and weaknesses of each conceptual model.

\section{RESULTS}

\section{Purpose and Application of Existing Models}

The seven models that addressed either MCC or the broader construct of patient complexity (Table 1$)^{10,12-17}$ were developed to inform research projects focused on patient-level predictors $^{10,15}$ or a combination of health system and patient factors. $^{12-14,16,17}$

Holzhausen and colleagues developed a conceptual framework, standardized instruments, and indicators for continuous monitoring of multimorbidity and associated healthcare needs in the population 65 years and older for a longitudinal epidemiological study. ${ }^{15}$ Their model includes concepts of multimorbidity and its consequences, quality of life, healthcare services utilization, personal and social resources that modify the association between multimorbidity and outcomes measures, and sociodemographic variables. ${ }^{15}$

Piette and Kerr developed a framework for understanding how comorbid chronic conditions complicate selfmanagement and care of patients with diabetes. ${ }^{13}$ Although designed in a diabetes-specific context, it can be applied more broadly. The authors assert that there are three typologies of comorbid conditions: 1) clinically dominant conditions that crowd out the provider management of other conditions; 2) concordant (or discordant) conditions that represent parts of the same (or different) pathophysiological risk profile and are likely to be (or not to be) the focus of the same disease management plan; and 3) symptomatic or asymptomatic conditions. ${ }^{13}$ The authors assert there are many ways in which comorbid chronic conditions impact medical care, selfmanagement, and outcomes of diabetic patients. ${ }^{13}$

Safford's Vector Model of Complexity was developed to inform clinical management of complex patients. ${ }^{10,16}$ This model defines patient complexity at a given time-point along socioeconomic, cultural, biological/genetic, environmental/ ecological and behavioral axes that interact as health determinants; multimorbidity is one aspect. ${ }^{10}$ In this model, patients can have greater vulnerability in one or more axes and axes contributing to complexity can change over time to reflect complexity's dynamic nature.

The Cumulative Complexity Model was also developed to inform clinical care of complex patients. ${ }^{16}$ Shippee and colleagues conceptualize complexity as an imbalance between patient workload from medical and non-medical demands and a patient's capacity to address demands. ${ }^{16}$ The authors note that workload-capacity imbalance can be dynamic because of feedback loops and changes over time in workload demands and patients' capacity to manage them.

Finally, the conceptual model by Capobianco and Lio applies a systems theory approach. ${ }^{14}$ The model depicts comorbidity as a dynamic system with several dimensions - clinical, genetic, therapeutic, and computational. ${ }^{14}$ The clinical dimension includes diagnostic tests and treatments, while the therapeutic dimension includes interventions aimed at restoring stationarity (homeostasis). ${ }^{14}$ The computational dimension "aims to embrace...complexities related to...other dimensions by a variety of inference approaches." 14 The model is inherently dynamic, proposing that health-related complexity occurs in a natural cycle of perturbation, transition, and return to stationarity. $^{14}$

While the previously discussed models were developed to inform research on patient-level predictors and clinical care, the remaining models were developed to inform performance measurement and quality improvement. As part of AHRQ Multiple Chronic Conditions Research Network (MCCRN) projects, Grembowski and colleagues define complexity as the gap between an individual's needs and the healthcare system's capacity to support those needs. ${ }^{12}$ The model's outcomes include care quality, quality of life, health and well-being. In this formulation of complexity, the model envisions quality improvement within healthcare organizations as means of reducing complexity. Complexity management is envisioned as responsibility shared between patients and healthcare organizations.

Giovannetti and colleagues developed the Performance Measurement for People with Multiple Chronic Conditions conceptual model. Key constructs include national priorities for improving healthcare (e.g., affordable care, safety); types of care (e.g., prevention, palliation), sites and providers of care (e.g., pharmacy, primary care); and patient and family goals and care preferences. ${ }^{17}$ This conceptual model is unique because it is focused on performance measurement. It does not explicitly outline patient, provider, and health system factors contributing to $\mathrm{MCC}$. 
Table 1 Summary of Prior Conceptual Models

\begin{tabular}{|c|c|c|c|c|c|}
\hline $\begin{array}{l}\text { Author, } \\
\text { Publication } \\
\text { Year }\end{array}$ & Model Purpose & $\begin{array}{l}\text { Patient-level } \\
\text { Factors in Model }\end{array}$ & $\begin{array}{l}\text { Patient-related } \\
\text { Factors in Model }\end{array}$ & $\begin{array}{l}\text { Health } \\
\text { system } \\
\text { Factors in } \\
\text { Model }\end{array}$ & Comments \\
\hline $\begin{array}{l}\text { Capobianco } \\
\& \text { Lio. } 2013^{14}\end{array}$ & $\begin{array}{l}\text { Apply a systems approach } \\
\text { to the understanding of } \\
\text { comorbidity and complexity } \\
\text { - Complexity > MCC }\end{array}$ & $\begin{array}{l}\text { Disease, genetic } \\
\text { information, age, stress }\end{array}$ & $\begin{array}{l}\text { Acute health and life } \\
\text { events }\end{array}$ & $\begin{array}{l}\text { Treatment and } \\
\text { diagnostic } \\
\text { decisions }\end{array}$ & $\begin{array}{l}\text { Very theoretical; } \\
\text { emphasizes dynamics and } \\
\text { change over time; limited } \\
\text { attention to patient } \\
\text { preference, environmental } \\
\text { factors, or specific } \\
\text { outcomes }\end{array}$ \\
\hline $\begin{array}{l}\text { Giovannetti } \\
\text { et al. } 2013^{17}\end{array}$ & $\begin{array}{l}\text { Design a conceptual } \\
\text { framework that addresses } \\
\text { MCC to inform } \\
\text { performance measurement } \\
\text { - Complexity = MCC }\end{array}$ & $\begin{array}{l}\text { Embedded in patient } \\
\text { preferences }\end{array}$ & $\begin{array}{l}\text { Social, environmental, } \\
\text { and policy contexts are } \\
\text { acknowledged }\end{array}$ & $\begin{array}{l}\text { Healthcare } \\
\text { services and } \\
\text { quality }\end{array}$ & $\begin{array}{l}\text { Focuses on episodes of } \\
\text { care more than longer } \\
\text { horizon or dynamics; } \\
\text { patient-level factors are not } \\
\text { explicitly outlined; cap- } \\
\text { tures "complexity" of } \\
\text { health system more than of } \\
\text { patient }\end{array}$ \\
\hline $\begin{array}{l}\text { Grembowski } \\
\text { et al. } 2014^{12}\end{array}$ & $\begin{array}{l}\text { Develop a framework to } \\
\text { guide improvements in care } \\
\text { for patients with MCC } \\
\text { - Complexity = MCC }\end{array}$ & $\begin{array}{l}\text { Chronic conditions, } \\
\text { patient values and } \\
\text { preferences }\end{array}$ & $\begin{array}{l}\text { Social support system; } \\
\text { economic, social and } \\
\text { physical factors are } \\
\text { mentioned }\end{array}$ & $\begin{array}{l}\text { Care quality, } \\
\text { patient } \\
\text { experience }\end{array}$ & $\begin{array}{l}\text { Complexity is defined as } \\
\text { gap between patient needs } \\
\text { and healthcare resources, } \\
\text { not an inherent patient } \\
\text { characteristic }\end{array}$ \\
\hline $\begin{array}{l}\text { Holzhausen } \\
\text { et al. } 2011^{15}\end{array}$ & $\begin{array}{l}\text { Develop a framework to } \\
\text { inform collection of } \\
\text { variables in a longitudinal } \\
\text { epidemiological study on } \\
\text { multimorbidity in older } \\
\text { adults } \\
\text { - Complexity = MCC }\end{array}$ & $\begin{array}{l}\text { Multimorbidity; } \\
\text { disability/function; social } \\
\text { participation; autonomy; } \\
\text { quality of life; personal } \\
\text { resources }\end{array}$ & Extrapersonal resources & Utilization & $\begin{array}{l}\text { Actionable in that specific } \\
\text { constructs and } \\
\text { relationships between them } \\
\text { are outlined; does not } \\
\text { account for healthcare } \\
\text { system factors, patient } \\
\text { preference, or dynamics }\end{array}$ \\
\hline $\begin{array}{l}\text { Piette and } \\
\text { Kerr } 2006^{13}\end{array}$ & $\begin{array}{l}\text { Present a framework for } \\
\text { considering the ways in } \\
\text { which comorbid chronic } \\
\text { conditions influence diabetic } \\
\text { patients' medical care, self- } \\
\text { management, and outcomes } \\
\text { - Complexity }>\text { MCC }\end{array}$ & $\begin{array}{l}\text { Chronic conditions; } \\
\text { general health status; self- } \\
\text { care; self-management } \\
\text { support; personal re- } \\
\text { sources and priorities }\end{array}$ & $\begin{array}{l}\text { Not explicitly included } \\
\text { in model }\end{array}$ & $\begin{array}{l}\text { Clinician } \\
\text { resources and } \\
\text { priorities }\end{array}$ & $\begin{array}{l}\text { Could be applicable to any } \\
\text { chronic condition } \\
\text { (although developed for } \\
\text { diabetes); describes the } \\
\text { interplay between index } \\
\text { disease management and } \\
\text { management of other } \\
\text { comorbid chronic } \\
\text { conditions; does not } \\
\text { account for patient } \\
\text { preferences }\end{array}$ \\
\hline $\begin{array}{l}\text { Safford et al. } \\
2007^{10}\end{array}$ & $\begin{array}{l}\text { Develop a framework } \\
\text { promoting congruence } \\
\text { between patients and } \\
\text { providers during healthcare } \\
\text { decisions } \\
\text { - Complexity }>\text { MCC }\end{array}$ & $\begin{array}{l}\text { Socioeconomics, biology/ } \\
\text { genetics, patient } \\
\text { behaviors }\end{array}$ & $\begin{array}{l}\text { Environment, ecology, } \\
\text { culture }\end{array}$ & $\begin{array}{l}\text { Not explicitly } \\
\text { included in } \\
\text { the model }\end{array}$ & $\begin{array}{l}\text { Names few specific } \\
\text { variables, but examples in } \\
\text { the text reduce the } \\
\text { abstractness of the model }\end{array}$ \\
\hline $\begin{array}{l}\text { Shippee et al. } \\
2012^{16}\end{array}$ & $\begin{array}{l}\text { Develop a patient-centered } \\
\text { model of complexity with } \\
\text { practical applicability to } \\
\text { analytic design and clinical } \\
\text { practice } \\
\text { - Complexity > MCC }\end{array}$ & $\begin{array}{l}\text { Anything that could } \\
\text { affect workload or } \\
\text { capacity }\end{array}$ & $\begin{array}{l}\text { Patient workload } \\
\text { drivers (job, family, } \\
\text { self-care, paperwork), } \\
\text { capacity drivers (pain, } \\
\text { function, social } \\
\text { support) }\end{array}$ & $\begin{array}{l}\text { Access, } \\
\text { utilization, } \\
\text { self-care, } \\
\text { burden of } \\
\text { treatment }\end{array}$ & $\begin{array}{l}\text { Posits that complexity is } \\
\text { driven by imbalance in } \\
\text { patient workload and } \\
\text { capacity; these constructs } \\
\text { are flexible and adaptable; } \\
\text { does not emphasize acute } \\
\text { events, health changes, or } \\
\text { dynamics or acknowledge } \\
\text { that patient may possess } \\
\text { capacity to meet a given } \\
\text { demand but choose not to, } \\
\text { if so doing does not align } \\
\text { with overall goals/ } \\
\text { priorities }\end{array}$ \\
\hline
\end{tabular}

Note: The designation "MCC=Complexity" does not imply that the articles fail to acknowledge factors besides MCC or that the articles assert that complexity is no more than MCC; rather, we have used "MCC=Complexity" to denote that the expressed objective of these articles relates to MCC (not complexity more broadly), but we included them because MCC is such an important aspect of complexity. The designation of "Complexity > MCC" indicates that the authors defined complexity more broadly than multimorbidity alone; for example, complexity could be defined as multimorbidity plus social or healthcare system factors

\section{Common Factors and Common Gaps across Models}

While these models offer considerable breadth in purpose and intended application, there are many common factors across models (Table 1). The most universally addressed factors were comorbidity or multiple chronic conditions, ${ }^{10,12,14,16}$ social support, ${ }^{12,15,16}$ and biological factors. ${ }^{10,14,15}$ The dynamic or longitudinal aspects of patient complexity were discussed in three models, ${ }^{10,14,16}$ and three models discussed healthcare system factors, including care quality and service delivery. ${ }^{12,14,16}$ 
Some models also noted physical or built environment in some capacity, ${ }^{10}$ as well as patients' values and preferences. ${ }^{17}$

We identified five gaps in existing models of patient complexity: patient preferences, contextual factors, dynamics of complexity, acute health shocks, and resilience. These gaps represent areas of importance to our conceptualization of complexity. While they were represented to various degrees in some models, they were missing or insufficiently captured in most models and no model incorporated all five of these aspects of complexity.

First, three models emphasized patients' preferences and personal priorities. ${ }^{12,13,17}$ The importance of patient preferences in self-management and healthcare system priorities cannot be overstated, as health systems are increasingly encouraged to provide patient-centered care. ${ }^{18}$ There may be variability in how and when patients want to be involved in making decisions about their care and their treatment goals. ${ }^{19}$ Patients may weigh trade-offs between potential treatment side effects and intended outcomes, coming to their own treatment decisions. ${ }^{20}$ Consistent with Giovannetti, ${ }^{17}$ we believe that patient preferences and expectations must be central to any model of complexity, because it is the lens through which all other factors are filtered.

Second, contextual factors, including interpersonal, organizational, and community factors, may drive complexity for patients and moderate the association between complexity and outcomes. Cultural and language barriers may interact with contextual factors to impact healthcare quality. ${ }^{21}$ While the included models highlighted limited contextual factors, none addressed the breadth of potential contextual factors impacting patients. Across the included models, the healthcare delivery environment, ${ }^{17}$ community resources and policies, ${ }^{12}$ sociocultural context encompassing financial resources and social support, ${ }^{10,13}$ physical environment, ${ }^{10}$ and social factors such as literacy level ${ }^{16}$ were mentioned with varying levels of focus.

Third, the dynamic nature of complexity among patients received little attention, although several models mentioned time and/or longitudinal measurement. ${ }^{10,12,14-17}$ Patient biology, healthcare needs, social support, services delivery, and preferences may change over time. Small changes in one domain may be linked to cascading changes in other domains. Changes in these factors may cause changes in a patient's capacity, resilience, and workload (Fig. 2). Workload includes all demands on energy and time associated with a patient's health-related experience, inclusive of demands borne by the patient, caregivers, employers, providers, or others affected by an individual's health issues. ${ }^{16}$

While workload (dashed line, Fig. 2) may gradually increase as a person approaches death, ${ }^{22,23}$ physical and cognitive capacity (solid line, Fig. 2) to manage this workload gradually decreases. These changes may not occur in a linear fashion. There may be fluctuations above and below each person's linear trend associated with acute shocks, consistent with trajectories of functional decline, which have been shown to be quite variable among Medicare beneficiaries, ${ }^{24}$ and, more broadly, among community-dwelling older adults. ${ }^{25}$ For example, a complex patient with cancer might begin the final year of life as highly functional, but experience a sharp functional decline in the last three months. ${ }^{24}$ Alternatively, a patient with chronic conditions and organ failure might experience a more fluctuating pattern of decline. ${ }^{24}$

Fourth, existing models tended to focus exclusively on chronic issues and did not highlight the impact that negative and positive acute "shocks" can have on complexity in the short-term or the longer-term. The Shippee Model emphasized the critical balance between demand and capacity, which implies the possibility of "tipping points," but the article does

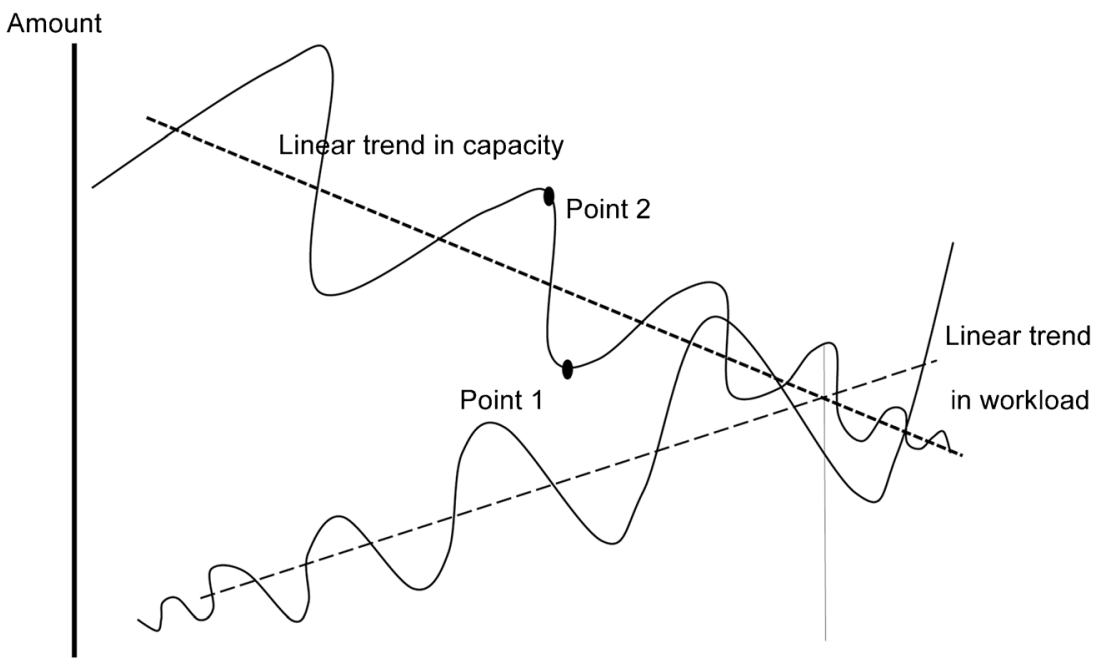

Age 40

Figure 2 Within-person changes over time in capacity and workload 
not explicitly discuss acute shocks. ${ }^{16}$ For example, a negative "shock" of a spouse's death would result in an immediate reduction in social support that would vastly complicate a patient's self-management and ability to manage his or her medical and non-medical needs (point 1 in Fig. 2). ${ }^{26}$ Alternatively, a positive "shock" could include children visiting a frail parent for several weeks, which would result in a short-lived increase in social support that might cause the patient's capacity to self-manage to fluctuate above their mean (point 2 in Fig. 2). ${ }^{27}$

The final identified gap was the important concept of resilience, which was not explicitly addressed in any of the existing models. Resilience refers to the capacity to remain well or bounce back following a physical, emotional, or social stressor. ${ }^{28}$ People facing similar health challenges may exhibit very different health trajectories following the stressor, reflecting differences in resilience. ${ }^{29-31}$ Much literature has focused primarily on psychosocial resilience in the face of stressful life events, but we invoke an emerging concept of resilience that incorporates both psychological and physical resilience and posits that both aspects contribute to recovery and successful aging. ${ }^{30,32-34}$ Resilience has been conceptualized both as a patient characteristic, which can change over time and may be influenced by learning or training, and as a dynamic process or whole-person response following a stressor. ${ }^{28,30}$ While Capobianco and Lio's model does not directly address resilience, they mention a related idea, perturbation and return to stationarity in complex systems. ${ }^{14} \mathrm{~A}$ distinct difference between the two concepts is that return to homeostasis may require medical intervention, while resilience is largely focused on factors inherent to the patient. The construct of resilience acknowledges variability in patients' ability to recover and persist following episodes of decompensation that result from unmet demands. Thus, even when a complex patient lacks capacity to meet a given demand, the long-term health effects may be mitigated by resiliency.

We posit that these five issues (patient preferences, contextual factors, dynamics, acute shocks, and resilience) are key aspects of understanding and addressing patient complexity. These gaps represented opportunities to build upon prior conceptual models, which we did in an iterative process until reaching the final version of our conceptual model.

\section{The Cycle of Complexity Model}

We present a conceptual model that builds upon the strengths of the reviewed models and addresses gaps discussed above (Fig. 3). ${ }^{16}$ Each construct has a subscript of "t" to denote its

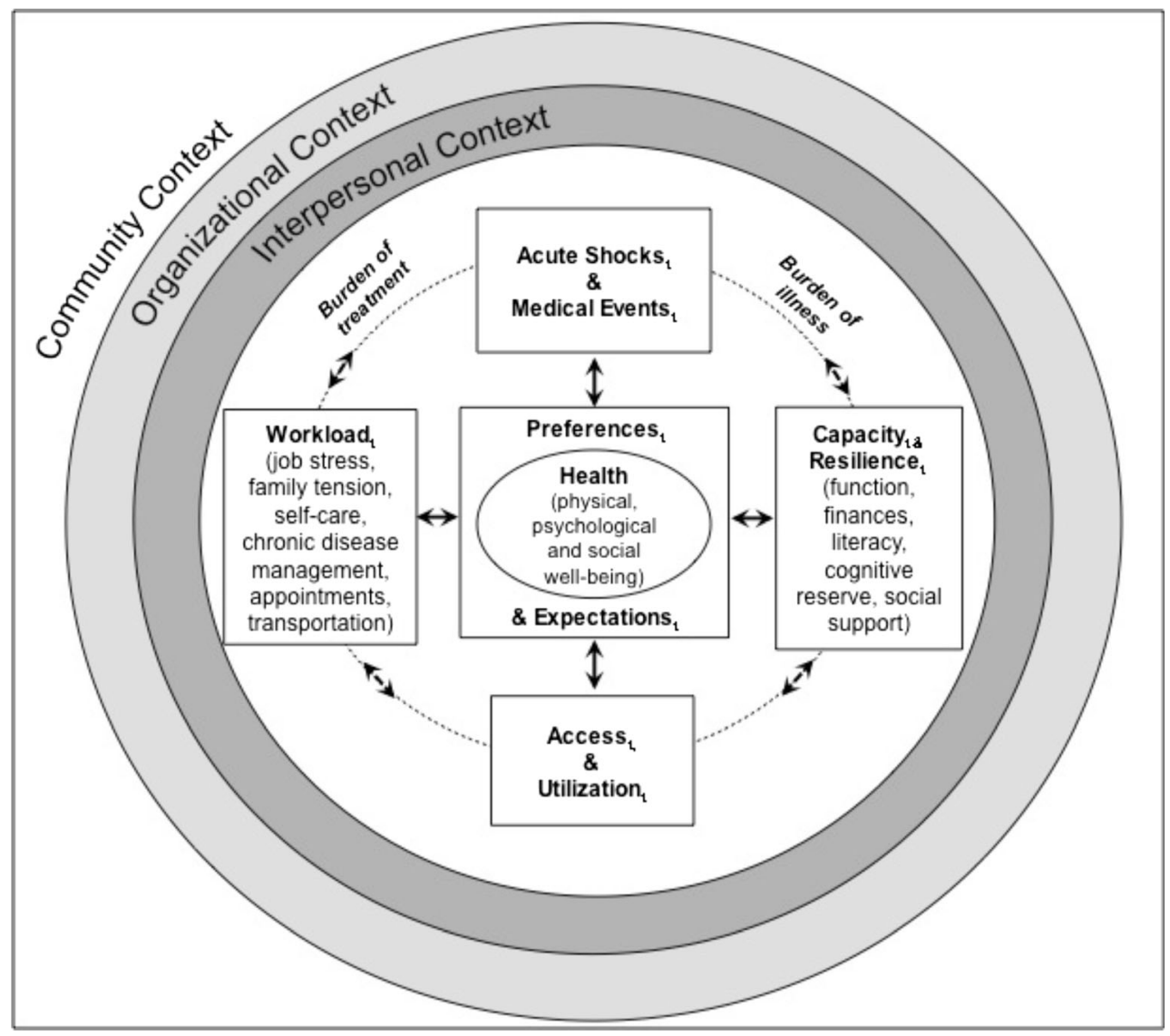

Figure 3 The Cycle of Complexity 
value at the present time and to imply that each construct can change over time. This new conceptual model can be used to understand within-person changes over time in these constructs (life cycle analysis), as well as between-person differences at a single point in time. The model also includes feedback loops (represented by double-headed arrows) enabling changing connections between constructs.

In the workload domain taken directly from Shippee and colleagues, ${ }^{16}$ we consider factors that increase the effort that an individual must expend to manage daily activities. Sources of increased workload are diverse and include stress resulting from job demands, family tension (e.g., either daily routine or acute conflicts), self-care and managing chronic diseases, scheduling and showing up for medical appointments, and coordinating transportation for self and family members.

Whereas factors in the workload domain detract from an individual's personal reserves and increase patient complexity, factors in the time-varying capacity and resilience domain positively affect the patient by equipping them with resources to effectively manage complexity. For example, high health literacy may increase a patient's capacity by enabling them to be a well-informed healthcare consumer. Other factors positively contributing to capacity include high physical functioning, having adequate financial resources, strong cognitive reserve, and robust social support. We view resilience as a time-varying construct that encompasses adaptive behaviors, thoughts, and feelings, as well as physical and biological reserve and protective factors. There is growing consensus that, although resilience is inherent within an individual, it is not a static trait; rather, resilience involves a skill set and resources that can be cultivated. ${ }^{35,36}$

The next domain of the Cycle of Complexity Model includes acute shocks and medical events. Acute shocks include unanticipated positive or negative changes in physical and/or mental health status. Medical events include major incidents such as a new diagnosis, heart attack, or stroke. Acute shocks and medical events may impact one another; thus, they are in the same overarching domain. Within the acute shocks and medical events domain, factors may either contribute to or mitigate patient complexity.

Access and utilization comprise the next domain. This includes factors that make healthcare either more or less accessible, such as insurance status, geographic availability, or language concordance. Utilization, a related concept, addresses healthcare seeking behavior and a patient's use of available services. Access and utilization may both increase or decrease patient complexity. For example, access and utilization of dialysis services may increase patient workload as well as increase patient health and well-being.

The health domain is at the center of the Cycle of Complexity Model and is enveloped in patients' preferences and expectations. Patients' preferences and expectations shape their treatment decision-making and perception of health.
Patients with $\mathrm{MCC} /$ complexity are faced with many decisions that amount to trade-offs between competing demands of medical goals and social/psychological goals. They may struggle to find the ideal balance between attending to medical conditions in order to control symptoms and avoid exacerbations, and yet avoiding a life that becomes dictated by appointment and treatment schedules, denial of pleasures, healthrelated financial burdens, and constant worry over future medical crises. ${ }^{37}$

The Cycle of Complexity Model also includes interpersonal, organizational and community factors adapted from the Social Ecological Model. ${ }^{38}$ We define the interpersonal context as a social and relational construct that includes immediate social support of family and friends. The organizational context includes professional and communitybased organizations, employers, schools, and healthcare organizations. Lastly, we define the community context as social groups, social media, and neighborhoods, including cultural factors. For some complex patients, these social-ecological factors are important contributors to complexity, even for patients whose complexity is not driven by having multiple chronic conditions. For example, a neighborhood might have a community walking group, which would help a patient maintain physical activity and increase peer social support, potentially decreasing their complexity.

\section{DISCUSSION}

At least seven conceptual models related to MCC or the broader construct of complexity have been published. While MCC was a focus of most of the included conceptual models, there were three models that considered complexity more broadly-the Grembowski, ${ }^{12}$ Shippee, ${ }^{16}$ and Safford ${ }^{10}$ Models. The authors of the Shippee Model ${ }^{16}$ posited that complexity is driven by an imbalance between patient workload and capacity, while complexity was defined in the Grembowski Model ${ }^{12}$ as the misalignment between patients' needs and the healthcare services rendered. The Safford Model also viewed complexity broadly by considering interactions between biological, socioeconomic, cultural, environmental, and behavioral forces that impact trade-offs and patient and provider decision making. ${ }^{10}$

The development of this conceptual model contributes to the literature in several ways. By taking a broader approach to the definition of factors comprising patient complexity, a richer measurement and analysis of complexity may better explain between-person differences at a point in time and within-person changes in complexity over time. The model can also inform analysis of complexity's impact on patient outcomes in cross-sectional analyses that compare outcomes between more and less complex patients or longitudinal analyses that examine within-person changes in outcomes over time. If more comprehensive measurement better explains 
variation in modifiable drivers of complexity, the Cycle of Complexity Model can inform the development of interventions and care models that effectively improve complex patients' care.

Our review process for including conceptual models excluded well-known clinical care models. For example, the Geriatric CompleXity of Care Index (GXI) is a validated comorbidity index that addresses disease severity and intensity for older adults with MCC. ${ }^{39}$ While the GXI may be important in the measurement and classification of complex patients, it is an index rather than a conceptual model. We also excluded Wagner's Chronic Care Model ${ }^{40,41}$ and the Model of Allostatic Load and Allostasis, ${ }^{42,43}$ because they were designed for clinical care delivery and organization, rather than as conceptual models. The Cycle of Complexity Model is likely to require refinement over time as the evidence base for MCC and complex patients is developed.

Given the increasing prevalence of MCC and complexity and the disproportionate share of health expenditures incurred by these patients, ${ }^{44,45}$ there is an urgent need to understand drivers and causal pathways through which complexity can be subject to intervention. Current care models for MCC patients are largely based on medical interventions provided in health systems. To improve care, these care models must include social and medical components to address the spectrum of factors driving complexity. Such multi-component socialmedical interventions are being tested in several local communities around the United States ${ }^{46}$ which will require concerted effort and multi-disciplinary collaboration between researchers. The Cycle of Complexity Model represents a framework for structuring dialogue, a research agenda and targets of intervention.

\section{Acknowledgements:}

Contributors: Helpful comments from Evelyn Chang, MD are acknowledged.

Funding/Support: Dr. Zullig is supported by a VA Health Services Research and Development (HSR\&D) Career Development Award (CDA 13-025) and Dr. Maciejewski is supported by a VA HSR\&D Research Career Scientist Award (RCS 10-391) and the Agency for Healthcare Research and Quality (R01HSO23085, RO1HS023099). Dr. Whitson is supported by the National Institute on Aging (R01AG043438, R24AG045050) and the Alzheimer's Association (NIRG-13-282202). Dr. Hastings is supported by VA HSR\&D (IIR 12052). This initiative was undertaken with support of the Duke Aging Center and Duke Pepper Older Americans Independence Center (P3OAG027816).

Role of the Funder/Sponsor: The funding organizations had no role in the design and conduct of the study; collection, management, anal$y$ sis, and interpretation of the data; preparation, review, or approval of the manuscript; and decision to submit the manuscript for publication.

\section{Prior Presentations: None.}

Conflict of Interest: The authors have no conflicts of interest to disclose. The views expressed in this article are those of the author(s) and do not necessarily represent the views of the Department of Veterans Affairs.
Corresponding Author: Matthew L. Maciejewski, PhD; Center for Health Services Research in Primary CareDurham Veterans Affairs Medical Center, 411 West Chapel Hill Street, Suite 600, Durham, NC 27701, USA (e-mail: Matthew.Maciejewski@va.gov).

\section{REFERENCES}

1. Boyd CM, Darer J, Boult C, Fried LP, Boult L, Wu AW. Clinical practice guidelines and quality of care for older patients with multiple comorbid diseases: implications for pay for performance. JAMA. 2005;294(6):716724.

2. Tinetti ME, Fried TR, Boyd CM. Designing Health Care for the Most Common Chronic Condition-Multimorbidity. JAMA. 2012;307(23):24932494

3. Brown R, Peikes D, Chen A, Schore J. 15-site randomized trial of coordinated care in Medicare FFS. Health Care Financing Review. 2008;30(1):5-25. Fall.

4. Brown RS, Peikes D, Peterson G, Schore J, Razafindrakoto CM. Six features of Medicare coordinated care demonstration programs that cut hospital admissions of high-risk patients. Health Affairs (Project Hope). 2012;31(6): 1156-1166. Jun.

5. Hirth V, Baskins J, Dever-Bumba M. Program of all-inclusive care (PACE): past, present, and future. Journal of the American Medical Directors Association. 2009; 10(3): 155-160. Mar.

6. Tinetti ME, Bogardus ST Jr, Agostini JV. Potential pitfalls of diseasespecific guidelines for patients with multiple conditions. New Engl J Med. 2004;351(27):2870-2874.

7. U.S. Department of Health and Human Services. Multiple chronic conditions-A strategic framework: Optimum health and quality of life for individuals with multiple chronic conditions. Available from: http://www. hhs.gov/ash/initiatives/mcc/index.html Accessed February 17, 2015.

8. Tinetti ME, Basu J. Research on multiple chronic conditions: where we are and where we need to go. Medical Care. 2014;52(Suppl 3):S3-6. Mar.

9. Grant RW, Ashburner JM, Hong CS, Chang Y, Barry MJ, Atlas SJ. Defining patient complexity from the primary care physician's perspective: a cohort study. Ann Intern Med. 2011;155(12):797-804.

10. Safford MM, Allison JJ, Kiefe CI. Patient complexity: more than comorbidity. the vector model of complexity. J Gen Intern Med. Dec 2007;22 Suppl 3:382-390.

11. Murayama H, Fujiwara Y, Kawachi I. Social capital and health: a review of prospective multilevel studies. J Epidemiol. 2012;22(3):179-187.

12. Grembowski D, Schaefer J, Johnson KE, et al. A conceptual model of the role of complexity in the care of patients with multiple chronic conditions. Medical Care. 2014;52(Suppl 3):S7-S14. Mar.

13. Piette JD, Kerr EA. The impact of comorbid chronic conditions on diabetes care. Diabetes Care. 2006;29(3):725-731. Mar.

14. Capobianco E, Lio P. Comorbidity: a multidimensional approach. Trends Mol Med. 2013;19(9):515-521. Sep.

15. Holzhausen M, Fuchs $\mathbf{J}$, Busch $\mathbf{M}$, et al. Operationalizing multimorbidity and autonomy for health services research in aging populations-the OMAHA study. BMC Health Serv Res. 2011;11:47.

16. Shippee ND, Shah ND, May CR, Mair FS, Montori VM. Cumulative complexity: a functional, patient-centered model of patient complexity can improve research and practice. J Clin Epidemiol. 2012;65(10):1041-1051. Oct.

17. Giovannetti ER, Dy S, Leff B, et al. Performance measurement for people with multiple chronic conditions: conceptual model. Am J Manag Care. 2013;19(10):e359-366.

18. Noel PH, Frueh BC, Larme AC, Pugh JA. Collaborative care needs and preferences of primary care patients with multimorbidity. Health Expectations. 2005;8(1):54-63. Mar.

19. Fried TR, Tinetti ME, Iannone L. Primary care clinicians' experiences with treatment decision making for older persons with multiple conditions. Arch Intern Med. 2011;171(1):75-80.

20. Fried TR, Tinetti ME, Iannone L, O'Leary JR, Towle V, Van Ness PH. Health outcome prioritization as a tool for decision making among older persons with multiple chronic conditions. Arch Intern Med. 2011;171(20):1854-1856.

21. Schyve PM. Language differences as a barrier to quality and safety in health care: the Joint Commission perspective. J Gen Intern Med. 2007;22(Suppl 2):360-361. Nov. 
22. Yang Z, Norton EC, Stearns SC. Longevity and health care expenditures: the real reasons older people spend more. J Gerontol B Psychol Sci Soc Sci. 2003;58(1):S2-10. Jan.

23. Schafer I, Hansen H, Schon G, et al. The influence of age, gender and socioeconomic status on multimorbidity patterns in primary care. First results from the multicare cohort study. BMC Health Serv Res. 2012;12:89.

24. Lunney JR, Lynn J, Foley DJ, Lipson S, Guralnik JM. Patterns of functional decline at the end of life. JAMA. 2003;289(18):2387-2392.

25. Ferrante LE, Pisani MA, Murphy TE, Gahbauer EA, Leo-Summers LS, Gill TM. Functional Trajectories Among Older Persons Before and After Critical Illness. JAMA Intern Med. 2015;175(4):523-529.

26. Zhang B, Mitchell SL, Bambauer KZ, Jones R, Prigerson HG. Depressive symptom trajectories and associated risks among bereaved Alzheimer disease caregivers. Am J Geriatr Psychiatr. 2008;16(2):145-155. Feb.

27. Choi H, Schoeni RF, Langa KM, Heisler MM. Older Adults' Residential Proximity to Their Children: Changes After Cardiovascular Events. The journals of gerontology. Jun 182014

28. Resnick B, Galik E, Dorsey S, Scheve A, Gutkin S. Reliability and validity testing of the physical resilience measure. The Gerontologist. 2011;51(5):643-652. Oct.

29. De Alfieri W, Borgogni T. Through the looking glass and what frailty found there: looking for resilience in older adults. J Am Geriatr Soc. 2010;58(3):602-603. Mar.

30. Hardy SE, Concato J, Gill TM. Resilience of community-dwelling older persons. J Am Geriatr Soc. 2004;52(2):257-262. Feb.

31. Levine M, Crimmins E. Not all smokers die young: a model for hidden heterogeneity within the human population. PloS One. 2014;9(2):e87403.

32. Whitson HE, Pieper CF, Cohen HJ. New light on an age-old issue. Mech Ageing Dev. 2008;129(11):673-674. Nov.

33. Walter-Ginzburg A, Shmotkin D, Blumstein T, Shorek A. A genderbased dynamic multidimensional longitudinal analysis of resilience and mortality in the old-old in Israel: the cross-sectional and longitudinal aging study (CALAS). Soc Sci Med. 2005;60(8):1705-1715.
34. Jacoby SF, Ackerson TH, Richmond TS. Outcome from serious injury in older adults. Journal of Nursing Scholarship. 2006;38(2):133-140.

35. Earvolino-Ramirez M. Resilience: a concept analysis. Nursing Forum. 2007;42(2):73-82. Apr-Jun.

36. Simpson GK, Dall'Armi L, Roydhouse JK, et al. Does Resilience Mediate Carer Distress After Head and Neck Cancer? Cancer Nursing. Feb 272015.

37. Morris RL, Sanders C, Kennedy AP, Rogers A. Shifting priorities in multimorbidity: a longitudinal qualitative study of patient's prioritization of multiple conditions. Chronic Illness. 2011;7(2):147-161. Jun.

38. McLeroy KR, Bibeau D, Steckler A, Glanz K. An ecological perspective on health promotion programs. Health Educ Q. 1988;15(4):351-377. Winter.

39. Min $\mathbf{L}$, Wenger $\mathbf{N}$, Walling $\mathbf{A M}$, et al. When comorbidity, aging, and complexity of primary care meet: development and validation of the Geriatric CompleXity of Care Index. J Am Geriatr Soc. 2013;61(4):542550. Apr.

40. Wagner EH. Chronic disease management: what will it take to improve care for chronic illness? Effective Clinical Practice. 1998;1(1):2-4. Aug-Sep.

41. Wagner EH, Austin BT, Von Korff M. Organizing care for patients with chronic illness. Milbank Q. 1996;74(4):511-544.

42. Gruenewald TL, Seeman TE, Karlamangla AS, Sarkisian CA. Allostatic load and frailty in older adults. J Am Geriatr Soc. 2009;57(9):1525-1531. Sep.

43. Stewart JA. The detrimental effects of allostasis: allostatic load as a measure of cumulative stress. J Physiol Anthropol. 2006;25(1):133-145. Jan.

44. Hwang W, Weller W, Ireys H, Anderson G. Out-of-pocket medica spending for care of chronic conditions. Health Affairs (Project Hope). 2001;20(6):267-278. Nov-Dec.

45. Wolff JL, Starfield B, Anderson G. Prevalence, expenditures, and complications of multiple chronic conditions in the elderly. Arch Intern Med. 2002;162(20):2269-2276.

46. Tavernise $\mathbf{S}$. Health Care Systems Try to Cut Costs by Aiding the Poor and Troubled. New York Times. 2015;22:2015. March. 